Article

\title{
Acoustic Intervention in a Cultural Heritage: The Chapel of the Royal Palace in Caserta, Italy
}

\author{
Umberto Berardi ${ }^{1,+}$, Gino Iannace ${ }^{2, *,+}$ and Carmine Ianniello ${ }^{3,+}$ \\ Received: 9 November 2015; Accepted: 15 December 2015; Published: 28 December 2015 \\ Academic Editor: Adrian Pitts \\ 1 Department of Architectural Science, Ryerson University, Toronto, ON M5B 2K3, Canada; \\ uberardi@ryerson.ca \\ 2 Dipartimento di Architettura e Disegno Industriale, Seconda Università di Napoli, Aversa 81031, Italy \\ 3 Dipartimento di Ingegneria Industriale, Università di Napoli “Federico II”, Napoli 80125, Italy; \\ ianniell@unina2.it \\ * Correspondence: gino.iannace@unina2.it; Tel.: +39-081-5010845; Fax: +39-081-8149266 \\ + These authors contributed equally to this work.
}

\begin{abstract}
The modern use of ancient heritage sites can be, to say the least, challenging from an acoustical perspective. In fact, modern needs may require acoustical interventions in contrast with the preservation issues of the cultural heritage. This paper deals with this topic in an UNESCO designated world heritage site, the Palatine Chapel of the Royal Palace in Caserta, Italy. Since this chapel is currently being used for meetings and music chamber concerts, the acoustical characteristics of the chapel, originally used for religious purposes, are investigated. Field measurements were undertaken to evaluate the acoustical performance of the empty chapel. The measurements were then used to calibrate and validate a computer simulation model. Different acoustical treatments are then considered and simulations are used to determine the related acoustical improvements. Finally, the benefits of different acoustical treatments which are respectful of the aesthetic and historical value of this cultural heritage are discussed.
\end{abstract}

Keywords: room acoustics; cultural heritage; reverberation; simulations; sound absorption panels

\section{Introduction}

Italy, one of the cradles of Western Civilization, has over 100,000 monuments such as churches, cathedrals, archaeological sites, and historical palaces, and it has the most United Nations Educational, Scientific and Cultural Organization (UNESCO) designated world heritage sites [1]. Among the 51 sites on the list there is the 18th-Century Royal Palace at Caserta with its park, the Aqueduct of Vanvitelli, and the San Leucio Complex. This large scale palace was created by the Bourbon King of Naples Charles III as the Italian response to the Palace of Versailles or the Royal Palace in Madrid [2]. The building exemplifies the Italian way of bringing together a magnificent palace with its park and gardens, as well as natural woodland, hunting lodges, and a silk factory. In fact, the site expresses the beauty of the integration of the architectural masterpiece into the natural landscape. The Palace, designed and built by the architect Luigi Vanvitelli, was the Bourbon dynasty's way to showcase the Kingdom of the Two Sicilies [2].

The Palatine Chapel, the focus of the current study, is located within the Royal Palace and was opened with a midnight mass on Christmas day, 1784 in the presence of King Ferdinand IV. The chapel emulates the analogous room of the Palace of Versailles. Originally dedicated to religious purposes, the magnificent chapel, located on the first floor of the Palace (Figure 1), is currently used for public events such as meetings and chamber music concerts. The new functions have shown the inadequacy of the acoustics of this marbled and highly decorated room (Figure 2). 


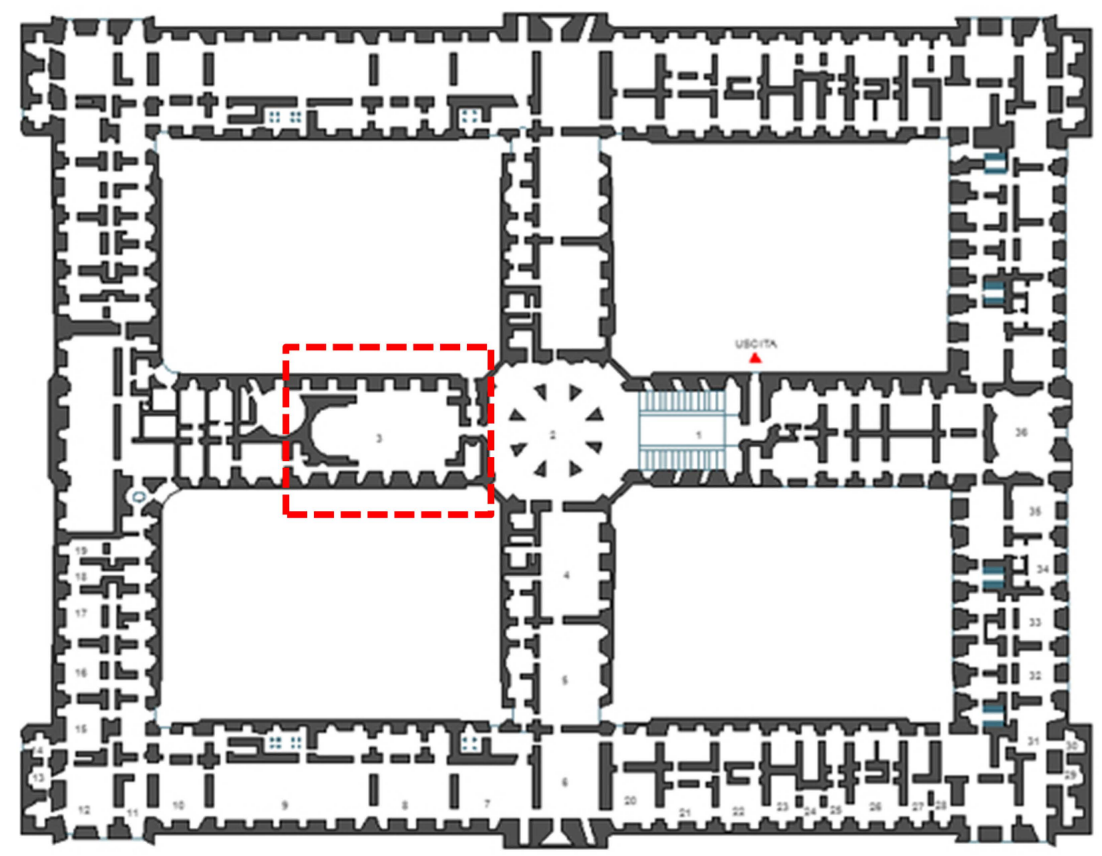

Figure 1. Plans of the Royal Palace in Caserta, showing the position of the Palatine Chapel.

The chapel is rectangular with a semi-circular apse at one end. On the opposite side to the apse is the entrance portal, above which is the royal tribune used by high dignitaries and the court ladies during sacral functions. Two galleries run along the side walls with double Corinthian columns that rise in support of a barrel vault with a richly decorated coffered ceiling. An abundance of colored marble characterizes most of the surfaces of the chapel. A large icon painted by Giuseppe Bonito portraying the Immaculate Conception is suspended in the apse, while originally organ pipes are placed on the two side galleries. The Chapel suffered severe damages during World War II, and was then restored according to the original design.

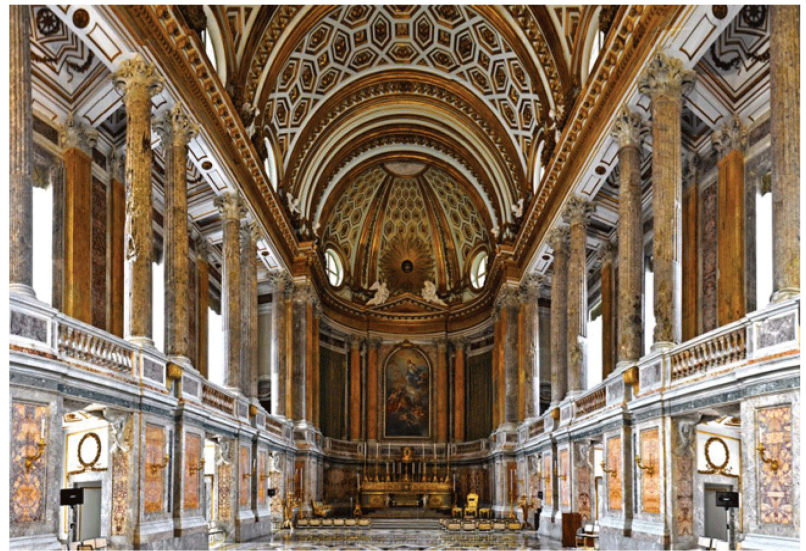

(a)

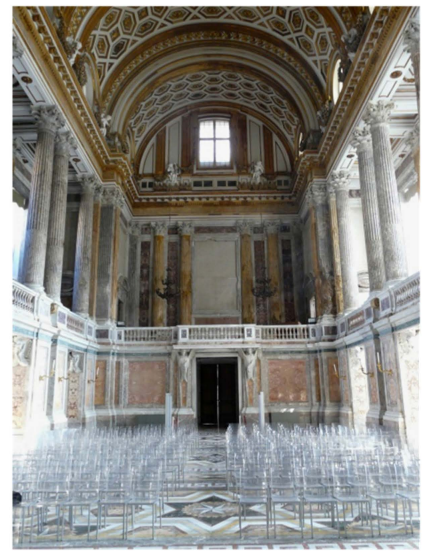

(b)

Figure 2. Views of the Palatine Chapel toward the apse (a) and toward the royal tribune (b).

Figure 3 shows the floorplan and a cross section of the Palatine Chapel with its main geometrical dimensions. The total length of the chapel is $37 \mathrm{~m}$, and the transversal width is $15 \mathrm{~m}$, while the vault has a maximum height of $25 \mathrm{~m}$. The inner volume is about $22,860 \mathrm{~m}^{3}$. It can be seen from Figure 2 that the chapel has highly decorated sound reflective surfaces. The instances of heritage preservation 
suggest the use of transparent plastic chairs for audience seating, as seen in Figure 2, in order to show the aesthetic beauty of the marble floor.
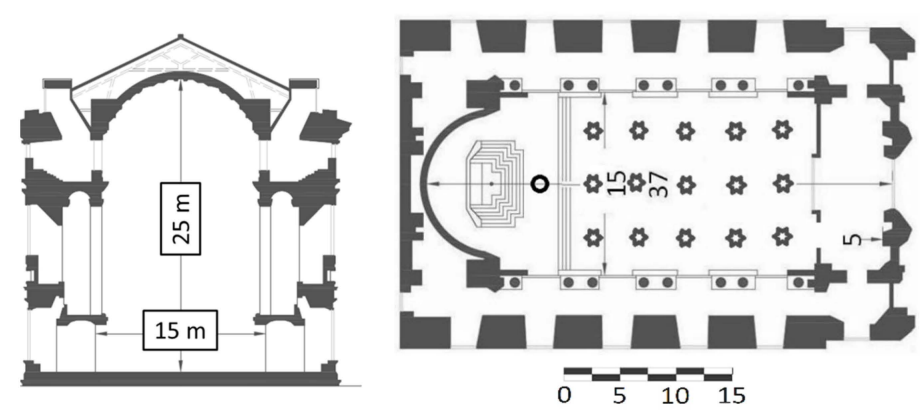

Figure 3. Cross section and plan of the Palatine Chapel, with location of the sound source (o) and of the receivers $(n)$.

The present study aims to explore feasible acoustical treatments to obtain better acoustic conditions for the events planned to be held in the chapel. Acoustical treatments had to consider the preservation of the heritage site. The study consisted of both field measurements inside the chapel and computer simulations of different intervention hypothesis with the aid of the software Odeon [3].

\section{Acoustic Survey}

\subsection{Acoustic Parameters of Analysis}

In room acoustics, the reverberation time is the most common parameter and it can be described as the persistence of sound after a source has stopped. In particular, the reverberation time is the time needed to have a reduction of $60 \mathrm{~dB}$ in the sound pressure level. In sound diffuse rooms, the reverberation time has the advantage of being steady throughout the space and predictable using simple formulas. However, it requires the capability of creating an energy gain of more than $60 \mathrm{~dB}$ over the background noise, before being able to measure the $60 \mathrm{~dB}$ sound pressure decay. In this paper, the early decay time (EDT) which is the slope of the best-fit linear regression line of the initial $10 \mathrm{~dB}$, between 0 and $-10 \mathrm{~dB}$, of the decay was evaluated as it is often shown to correlate better to the early reverberation effect in the room.

Several acoustic parameters defined in the ISO 3382-1 [4] were analyzed. These parameters have been defined in order to better describe the perception of a sound field, even though their prediction depends on many factors, such as the relative position of sources and receivers. In particular, this study focused on the values assumed by the center time, the clarity, and the definition.

The center time $\left(T_{s}\right)$ is defined as the time of the center of gravity of the squared impulse response of the sound energy, and it is related to the balance between early sound and delayed sound respect to the $\mathrm{T}_{\mathrm{s}}$ value. In reverberant rooms such as churches, where late reflections reach listeners with a long delay, $\mathrm{T}_{\mathrm{s}}$ can assume values up to several hundreds of milliseconds. Late sound contributes to have a long reverberation of the room and although it may improve the perception of the music, it is generally detrimental for listening to speeches.

The clarity measures the balance between the useful and detrimental sound for the listening perception. It represents the degree to which different reflections arrives and are perceived by the listener, and it is assessed as an early-to-late arriving sound energy ratio. This ratio can be calculated for either a $50 \mathrm{~ms}$ or an $80 \mathrm{~ms}$ early time limit, depending on whether it relates to conditions for speech or music respectively. In particular, the $C_{80}$ is defined as the ratio, expressed in decibels, of the early energy (from 0 to $80 \mathrm{~ms}$ ) over the late reverberant energy (from $80 \mathrm{~ms}$ to infinite).

The definition $\left(D_{50}\right)$ considers the early arriving sound energy over the total sound energy and it is calculated using $50 \mathrm{~ms}$ as the early time limit. 
Finally, the parameter of sound strength $(G)$ was assessed since this is representative of the subjective level of sound, and it is defined as the gain from the sound pressure level, which is produced by the same sound source with the same power level in a free field at a distance of $10 \mathrm{~m}$ from the sound source.

In order to establish suggested values of the different monaural acoustic parameters considered in this study different references were used. In this phase, it was important to select the most adequate function for this room. In order to guarantee a certain flexibility in the use, the room was supposed to host public meetings with speech comprehension (talks and receptions are common in this room), but also some baroque chamber music or small orchestra listening. The different requests of the several sound messages required some compromises in the acoustics goals. Using recent studies about the typical listening preference in sacred spaces [5-7], the following criteria were finally established:

- The early decay time (EDT) should assume values between $1 \mathrm{~s}$, a value adequate for a clearer perception of speeches, and $2.5 \mathrm{~s}$, a value adequate for music listening preference. In churches reverberation time and early decay time values well above $3 \mathrm{~s}$ are common and may well fit for example with organ music. However, since this kind of music is not contemplated in the programming of the Palatine chapel anymore, a shorter reverberation was considered necessary;

- The center time $\left(T_{s}\right)$ should assume values below $100 \mathrm{~ms}$ for a clearer perception of speeches, while it may assume greater values, up to 200 or $250 \mathrm{~ms}$ for music listening preference;

- The clarity $\left(\mathrm{C}_{80}\right)$ expressing the balance between the early and late arriving energy, should have an higher value if the goal is to separate the initial sounds from the diffuse ones and making the discrete sounds stand apart from each other. For the purposes of good listening conditions of music, it is generally preferable that $C_{80}$ should be in the range between $-2 \mathrm{~dB}$ and $2 \mathrm{~dB}$, while it is expected to be above $2 \mathrm{~dB}$ if speech perception is a priority;

- The definition $\left(D_{50}\right)$ which may assume values from 0 to 1 , should be above 0.50 for a good speech comprehension.

Obviously, the preferred values for the different parameters refer to fully occupied conditions so in a room such as the Palatine chapel, were the audience would represent the main sound absorbing surfaces, it is important to analyze the effect of the presence of the audience.

\subsection{Acoustic Measurements}

The sound source used to perform acoustic measurements consisted of a dodecahedron loudspeaker Peeker Sound JA12 (Peeker Sound Corportation, Reggio Emilia, Italy). MLS signals of order 16 with a length of $5 \mathrm{~s}$ were generated by a $01 \mathrm{~dB}$ Symphonie system. The sound pressure was recorded with a ${ }^{1 / 2}$ " microphone GRAS 40 connected with a preamplifier $01 \mathrm{~dB}$ PRE $12 \mathrm{H}$. The floor plan in Figure 3 shows the location of the sound source and of the fifteen receivers. The sound source was placed at the height of $1.5 \mathrm{~m}$ over the floor at the center of the area in front of the altar where musicians are usually located during concerts. The measurement microphone was placed at the height of $1.5 \mathrm{~m}$ over the floor too. Measurements were done both in the empty conditions of the chapel or with transparent chairs that are generally used (Figure 2).

The recorded impulse responses were then elaborated with the software Dirac 4.0 [5], and several acoustic parameters defined in the ISO 3382-1 [4], such as the early decay time (EDT), the center time $\left(T_{S}\right)$, the clarity $\left(C_{80}\right)$, and the definition $\left(D_{50}\right)$ were analyzed.

Figure 4 reports the measured values of EDT, $T_{s}, C_{80}$, and $D_{50}$, averaged among the fifteen receiver locations together with the intervals of the standard deviation for each octave band from $125 \mathrm{~Hz}$ to $4 \mathrm{kHz}$. All the measurements were done in unoccupied conditions. Obviously, the audience would have had an absorbing effect with a consequent reduction of the reverberation and hence of the EDT and $\mathrm{T}_{\mathrm{s}}$. However, the results of the measurements suggested that the hall in the observed state is clearly over reverberant and it is not well suited neither for chamber music nor for the intelligibility of speech. This led to study the possibility to introduce in this room some acoustic treatments. 
Acoustic measurements with the presence of chairs were also realized using the same measurement equipment and setup described previously. The measurement with the chairs showed no significant difference in the reverberation parameter (EDT), while other parameters, such as $\mathrm{C}_{80}$ or $T_{s}$ had more remarkable difference within the room. In fact, the sound scattering realized by the chairs reduced the clarity while increased the center time.
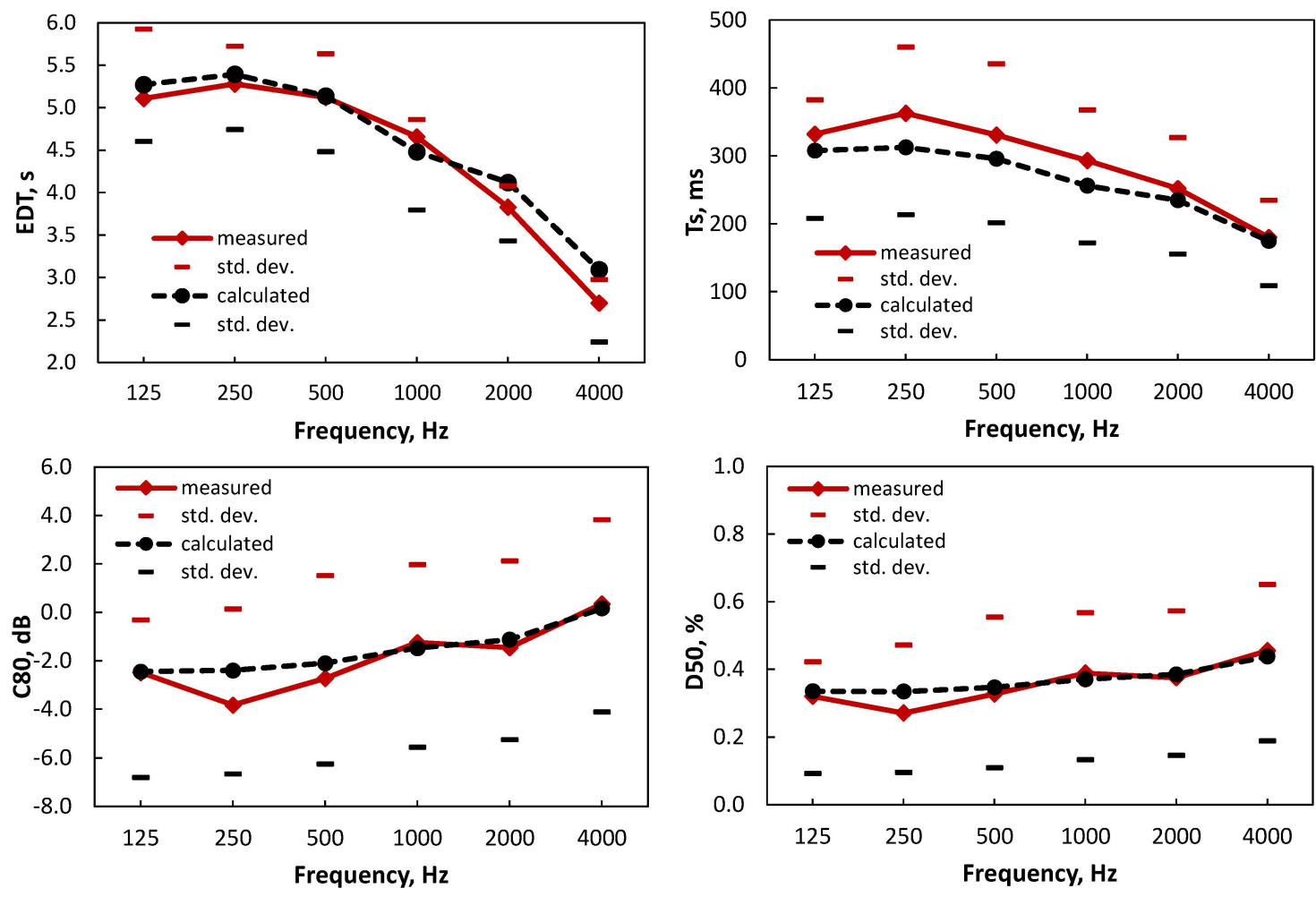

Figure 4. Comparison between measured and simulated results averaged among the 15 receiver positions of four room acoustic parameters, EDT, $\mathrm{T}_{\mathrm{s}}, \mathrm{C}_{80}$, and $\mathrm{D}_{50}$, and their standard deviations.

\section{Computer Simulations}

\subsection{The Virtual Model}

To obtain realistic data for the Palatine Chapel in actual use, including the effect of audience, computer simulations were carried out using the software Odeon [3]. This software model was then used to study the effect of temporary sound absorbing systems that can be adopted in the respect of the architectural value of the venue.

Odeon uses the principles of the geometrical acoustics and adopts a hybrid calculation method that combines the image source method and the ray-tracing method. The approach used by the software merges the best features of both models, since the image source method is used for the early-scattered rays of the first reflections, while a ray-tracing technique which also considers the surface scattering according to a Lambert's cosine law, is used for the more statistically computed late part of the impulse response [8-10]. Early reflections are generated by point sources for which the reflection order is less than or equal to the Transition Order (TO). The early reflections take into account the scattering properties of the surfaces. Every time a ray is reflected at a surface, the position of an image source is found. In this early part of the impulse response calculation, rays are only used indirectly to detect image sources that are likely to be valid. The image sources are then split into a specular contribution and a scattering contribution which consists of secondary sources on the image-source surfaces, allowing for a realistic calculation of early scattering. All reflections that are not accounted for by the early reflection method are treated by the late-reflection method. Every 
time a late ray is reflected at a surface, a secondary source is generated, having directivity varying according to Lambert's law. The late-reflection process keeps the reflection density constant in order to reduce the calculation time.

Usually, a computer software simulation requires a first step aimed at the development of a model of the space as it exists and for which acoustic measurements are available. Unavoidable approximations about the geometry and the acoustic behavior of materials must be faced with. A second step consists of the comparison between measured and simulated parameters which allows a suitable calibration of the acoustic model in order to reduce the difference between measured and simulated acoustical parameters to minimal values or at least to a value below the just noticeable difference (JND) of each parameter. After having obtained a virtual model that represents adequately the observed state of a room, desired changes or insertions are considered [11,12].

In situ checks and detailed 3D drawings of the Palatine Chapel allowed the realization of the reticulated version of the geometry of the room (Figure 5). The number of surfaces in the model was 3849. The estimated inner surface amounted to $15,864 \mathrm{~m}^{2}$. Clearly, many details of the CAD drawings could not be handled. Based on previous experience and software suggestions for the given volume of the simulated room, the simulations were performed using the following parameters: $\mathrm{TO}=2$, impulse response length $=6 \mathrm{~s}$., resolution $=3 \mathrm{~ms}$, and number of rays $=50,000$. Other parameters were assigned the default values of the software.

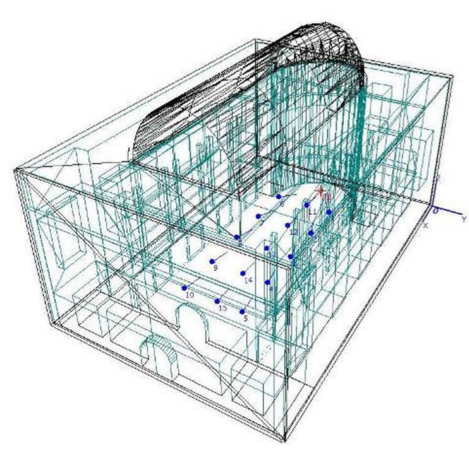

(a)

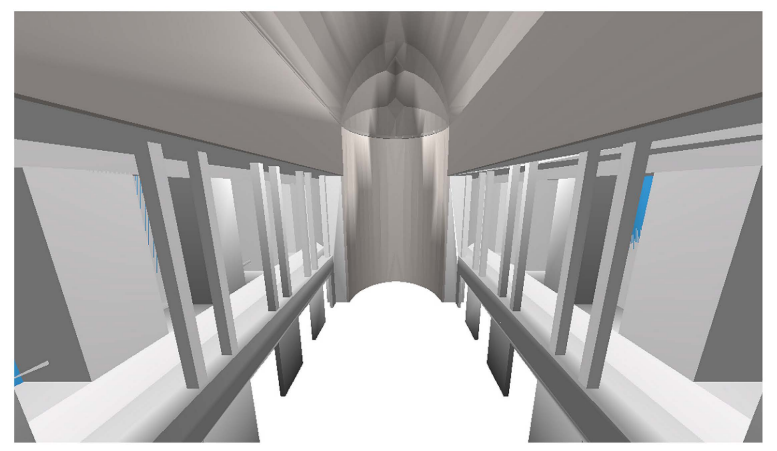

(b)

Figure 5. Palatine Chapel: reticulated geometry (a) and rendering as given by Odeon (b).

\subsection{The Calibration of the Virtual Model}

Most of the internal surfaces of the Palatine Chapel are constituted by flat marbles, which is an acoustically reflective material. The vault is made of a thick structure composed of cocciopesto, a lime mortar with crushed pottery. A relatively small fraction of the inner envelope is constituted of windows, doors and a few canvases, which could have a more sound absorbing behavior.

The initial values of the sound absorption $(\alpha)$ and sound scattering (s) were selected from literature data [12-17]. Then, in order to validate the acoustic model, measured averaged values of the different parameters were compared with the corresponding values calculated with the software. An iterative procedure was used to reduce the difference between the measured and calculated values. This implied little adjustments to the sound absorption and scattering coefficients [13]. In order to maintain the simplicity of the model together with its practicality, richly decorated surfaces were modelled as flat ones while the absorption and scattering coefficients were modified accordingly [17].

Figure 4 displays the results of the calibration of the virtual model of the Palatine Chapel, as well as the measured parameters, and it shows that the virtual model was able to obtain results particularly close to the measured ones. When measured and simulated are compared, it is a common practice in room acoustics to evaluate them in terms of the JND, the subjective limen of the specific parameter. This approach follows the common assumption that "what cannot be heard can be neglected" [14-16]. According to the standard ISO 3382 [4], the JND of the EDT is $5 \%$ of its value, while that of $T_{\mathrm{S}}$, 
$\mathrm{C}_{80}$, and $\mathrm{D}_{50}$ should be $10 \mathrm{~ms}, 1 \mathrm{~dB}$, and 0.05 , respectively. Thus, the precision of the simulated parameters was assessed in terms of number of JND. The results of the difference expressed in JND as receiver-averaged values and the relevant standard deviation for each octave band showed satisfactory values (Figure 4). The highest errors were found in the octave band of $4 \mathrm{kHz}$ for the EDT, and in that of $250 \mathrm{~Hz}$ for the $\mathrm{T}_{\mathrm{s}}, \mathrm{C}_{80}$, and $\mathrm{D}_{50}$. Overall, results in Figure 4 shows that the calibration was highly satisfactory.

In order to assess the effect of occupancy, the area where chairs are generally located was simulated as a series of boxes with a height of $0.8 \mathrm{~m}$, with absorption coefficients typical of lightly upholstered seats, as reported in Table 1 [17-19]. In the virtual model, the area occupied by the public is $200 \mathrm{~m}^{2}$. Figure 6 shows the plan distribution of the occupancy, which was modeled as boxes.

Table 1. Absorption and scattering coefficient used in the simulated model, data taken from [13-17].

\begin{tabular}{|c|c|c|c|c|c|c|c|}
\hline \multirow{2}{*}{ Material } & \multicolumn{6}{|c|}{ Absorption $(\alpha)$} & \multirow{2}{*}{ Scattering (s) } \\
\hline & $125 \mathrm{~Hz}$ & $250 \mathrm{~Hz}$ & $500 \mathrm{~Hz}$ & $1000 \mathrm{~Hz}$ & $2000 \mathrm{~Hz}$ & $4000 \mathrm{~Hz}$ & \\
\hline $\begin{array}{l}\text { Hard } \\
\text { walls }\end{array}$ & 0.048 & 0.047 & 0.045 & 0.05 & 0.053 & 0.03 & 0.05 \\
\hline Ceiling & 0.145 & 0.13 & 0.14 & 0.145 & 0.098 & 0.06 & 0.01 \\
\hline Windows & 0.35 & 0.25 & 0.18 & 0.12 & 0.07 & 0.02 & 0.05 \\
\hline Audience & 0.51 & 0.64 & 0.75 & 0.80 & 0.82 & 0.78 & 0.70 \\
\hline
\end{tabular}

The effect of the occupancy and the exact location of the source in historical churches have recently received increasing attention due to the highly reflective characteristics of these spaces $[17,20]$. In previous studies, it was found that the presence of the audience in churches determines a significant improvement of the monaural acoustical parameters, especially since the reverberation reduces once the presence of the audience is considered. Reversely, the sound source position has generally a limited effect over the reverberation time and a more significant impact on other acoustical parameters, as these strongly depend on the source-receiver position.

The results in Figure 7 show that the presence of the public is not sufficient to make the acoustics of the chapel in line with the goals reported in Section 2. Consequently, some acoustic correction treatments based on sound-absorbing surfaces were implemented. These treatments are considered necessary since the early decay time in fully occupied conditions still resulted to be above $3 \mathrm{~s}$ at middle frequencies.

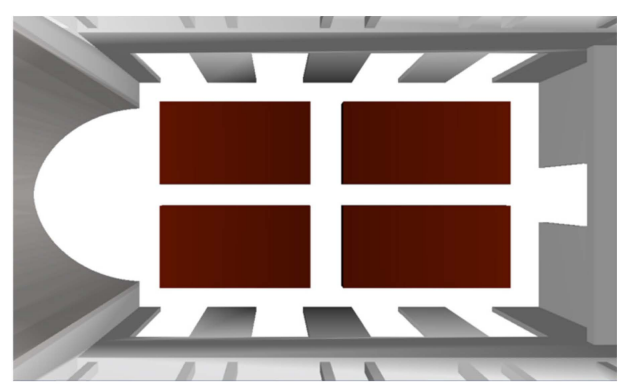

(a)

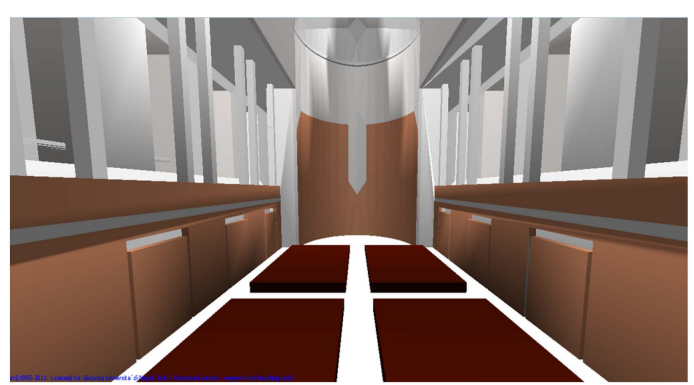

(b)

Figure 6. Plan distribution of the location of the audience (a), and position of banner treatments on the sides and in the apse (b). 

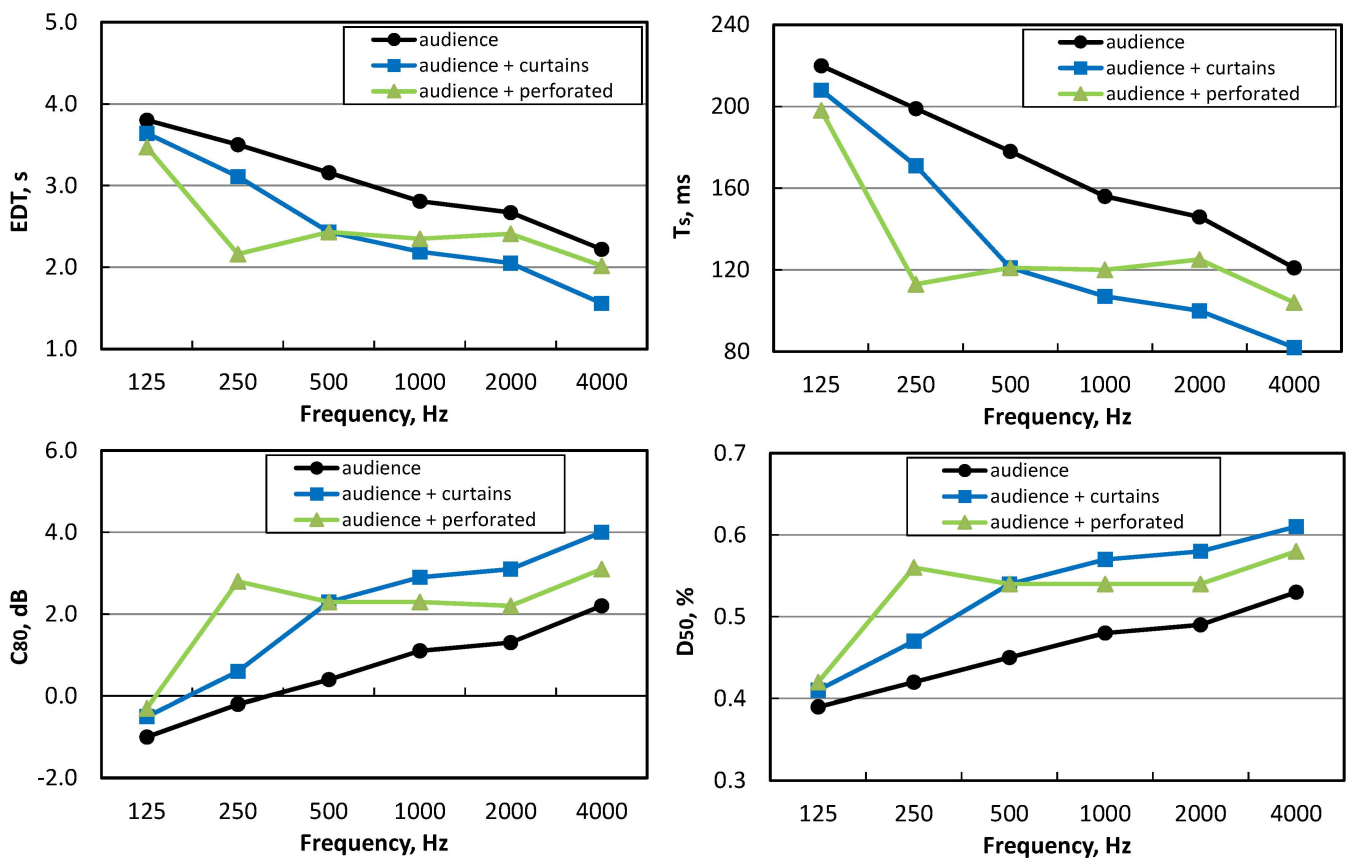

Figure 7. Simulation results obtained considering the presence of the audience (full occupancy), and with the acoustic absorbing curtains or perforated panels along lateral walls and in the apse.

\section{Acoustic Treatments}

Historic buildings, such as the Palatine Chapel, are heritage buildings whose cultural value prevents invasive or irreversible interventions. In this case, given the completely marbled nature of all the surfaces, permanent acoustic treatments to the room surfaces were not allowed. The need to create acoustic conditions closer to the actual needs led to evaluate removable elements that could be mounted and dismounted easily for specific events. Among the different acoustic treatment options, it was considered the possibility to adopt transparent vibrating banners, eventually micro-perforated, as well as heavy curtains.

Vibrating panels and perforated (or micro-perforated) ones once mounted at a given distance from a back rigid wall provide significant absorption at low frequencies. According to the theory, the largest absorption of vibrating panels occur for a distance from the rear wall of a quarter of the wavelength [21]. Micro-perforation in glazing or polycarbonate transparent panels were considered as a solution to get an absorber with a minimal visual presence. These panels being micro-perforated (with holes as small as $0.1 \mathrm{~mm}$ ) behave as Helmholtz devices, but without the normal resistive material. The holes are drilled mechanically and provide absorption through high viscous losses as air passes through the holes. Micro-perforated transparent absorbers have reached an increasing attention since they are transparent when looked at from straight on, although at oblique angles the holes become more apparent although the surface is still translucent [21]. Panels with holes dimeters ranging between 0.1 and $0.2 \mathrm{~mm}$ and with a percentage of holes in the range between $8 \%$ and $10 \%$ of the surface were considered. Panels with a surface density of $0.48 \mathrm{~kg} / \mathrm{m}^{2}$ and a thickness of $1.41 \mathrm{~mm}$ were then selected.

Another category of acoustics treatments that was considered is that of heavy textile materials. The absorption of these surfaces have received increasing attention in room acoustics application [22]. Add curtains sustained by rigid frame next to the base of the lateral walls could guarantee high absorption especially at high frequency. Moreover, if the curtains were mounted at a given distance from the back wall, the sound absorption would also be higher at lower frequencies, as a consequence of the smaller impedance of the sound wave far from the wall. 
Obviously, the specific effect of the absorption of curtains would depend on their distance from the back walls, but the typical drapes of curtains determine a significant variation of their distance from the rigid backing walls. This means that an exact determination of the sound absorption could not be defined. In order to simulate the effects of curtains, the literature values reported by Cox and D'Antonio for heavy curtains with a density of $610 \mathrm{~g} / \mathrm{m}^{2}$ were used [22].

The absorption coefficient values of the different acoustic treatments considered for the acoustic intervention are reported in Table 2. Overall, the acoustic treatments consisted of 250 square meter panels, mainly distributed along the lateral walls each one with a height of $3.5 \mathrm{~m}$ from the floor (Figure 6). The treatments were considered as temporary elements to display in the room in occasion of specific events. In particular, the transparent vibrating panels, absorbing the low frequency could guarantee a more tonal balanced acoustics of the room, which would be highly beneficial for speech listening; reversely, the introduction of heavy curtains would represent an elegant way to reduce the reverberation of the room, although their acoustic effect would be more appreciable at higher frequencies.

Table 2. Absorption coefficient of the acoustic treatments proposed in the Palatine chapel.

\begin{tabular}{ccccccc}
\hline \multirow{2}{*}{ Acoustic Treatment } & \multicolumn{7}{c}{ Frequency (Hz) } \\
\cline { 2 - 7 } & $\mathbf{1 2 5}$ & $\mathbf{2 5 0}$ & $\mathbf{5 0 0}$ & $\mathbf{1 0 0 0}$ & $\mathbf{2 0 0 0}$ & $\mathbf{4 0 0 0}$ \\
\hline $\begin{array}{c}\text { Transparent } \\
\text { micro-perforated panel }\end{array}$ & 0.15 & 0.70 & 0.40 & 0.30 & 0.20 & 0.15 \\
Heavy curtain banner & 0.10 & 0.20 & 0.40 & 0.50 & 0.60 & 0.70 \\
\hline
\end{tabular}

Figure 7 shows the acoustic parameters of the fully occupied room and the effects of the addition of banners placed on the side walls and in the apse. It can be noticed that the chapel still remains with an excess of reverberation showing the typical behavior of large churches influenced by air absorption at high frequencies [23]. Overall, the simulated values showed that the investigated room with the proposed acoustic corrections has acoustical properties that could be considered adequate for musical performance.

Figures 8 and 9 report the color maps at $1 \mathrm{kHz}$ of the $\mathrm{T}_{30}, \mathrm{C}_{80}$, and STI in the configuration with the audience and with the heavy curtains and vibrating transparent micro-perforated panels respectively. The figures show that the homogeneity of the sound field through the room also with the introduction of sound absorbing treatments along the two sides. At middle frequencies, the area where the audience seats would have a reverberation time equal to $2.6 \mathrm{~s}$ with the treatments of the heavy curtain banners and to $2.8 \mathrm{~s}$ with the vibrating micro-perforated panels (Figure 7).

The clarity reduces with the distance from the sound source, showing a remarkable behavior from values up to $8 \mathrm{~dB}$ closer to the sound source to values between $-2 \mathrm{~dB}$ and $\pm 2 \mathrm{~dB}$ in the rest of the chapel, both with the heavy curtains as well as with the vibrating panels.

Finally, in order to assess the possibility to use this room for meetings, which involve speech listening, the Speech Transmission Index (STI) was considered. This parameter represents the degree of amplitude modulation in a speech signal and refers to the distortion in speech signals caused by reverberation, echoes, and background noise. This index can assume values between 0 and 1, being greater than 0.5 for favorable speech conditions.

Results in Figures 8 and 9 show that the STI would be acceptable in the first half of the audience area, while the area farther from the sound source (simulated in the apse) would have a STI value around 0.45 . Such a value generally corresponds to a "poor" speech listening condition. However, it should be stated that these results were obtained with an omnidirectional sound source. This means that a sound reinforcement system consisting of directive loudspeakers should be used for a better speech listening in order to have improved STI values even in the back of the Chapel if this has to host events were highly speech intelligibility is required. 

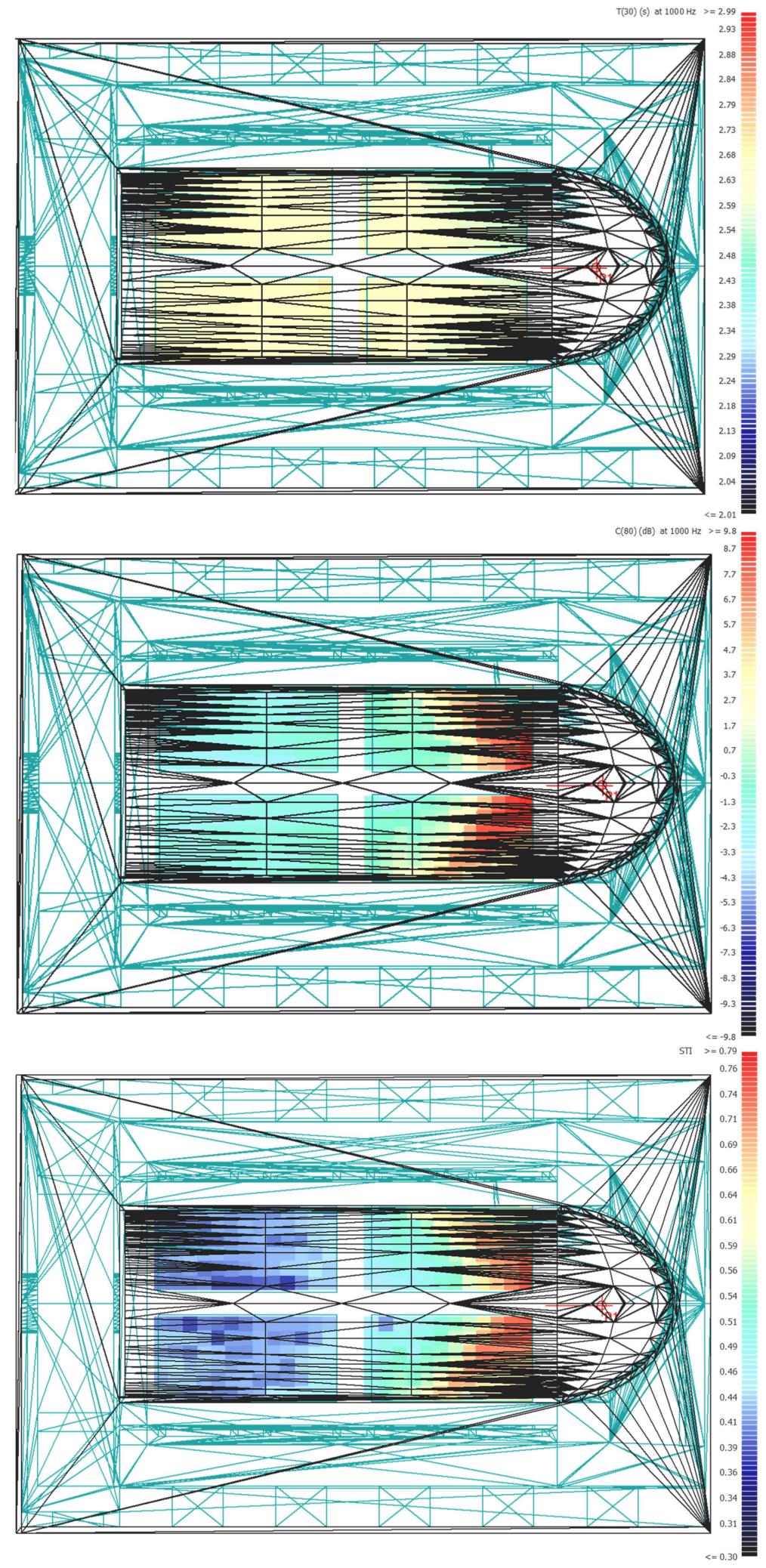

Figure 8. Color maps at $1 \mathrm{kHz}$ of the $\mathrm{T}_{30}, \mathrm{C}_{80}$, and $\mathrm{STI}$ in the configuration with the audience and the acoustic treatments heavy curtain banners (the maps only cover the area where the audience seats). 

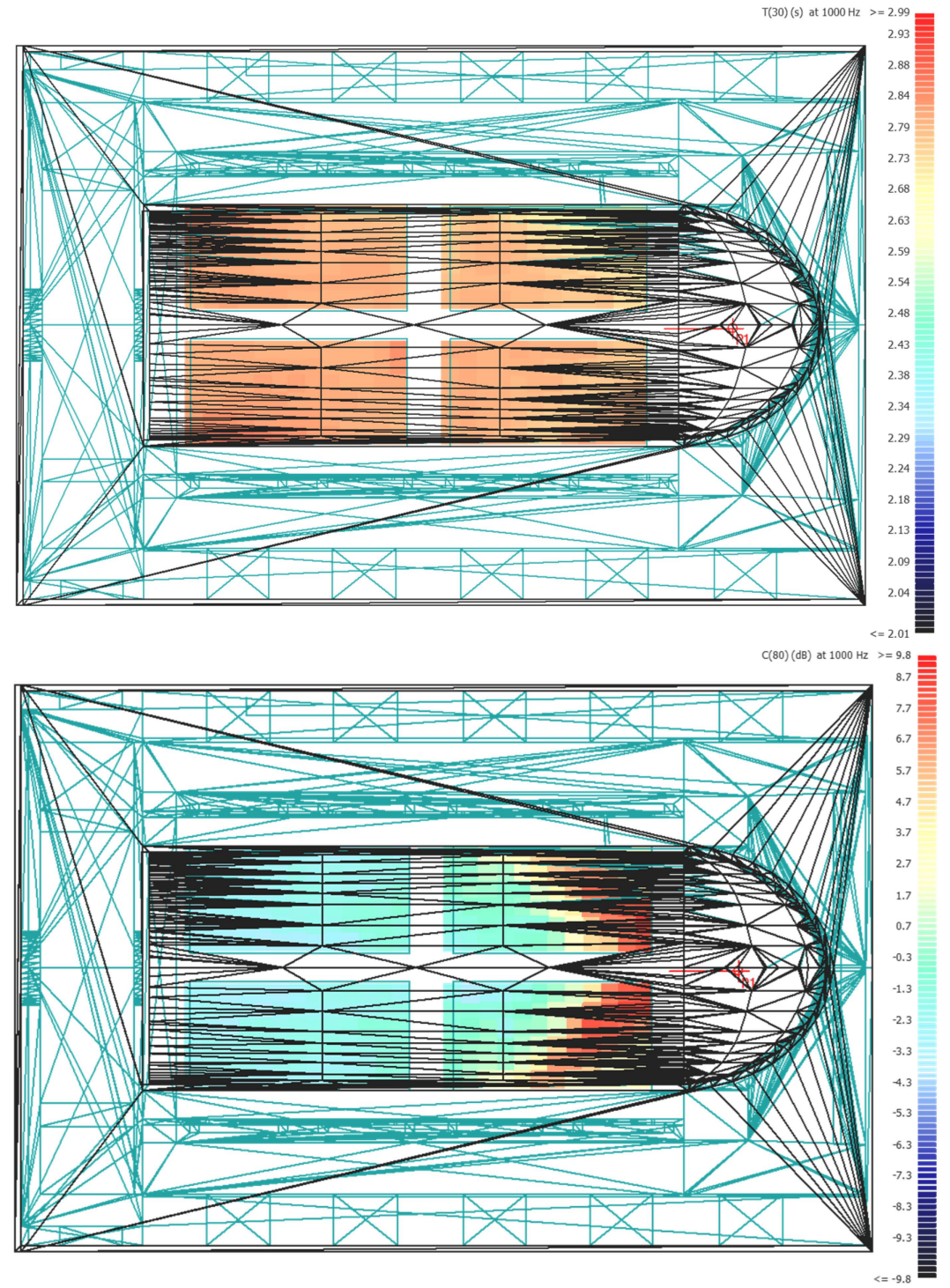

5ा1 $>=0.79$

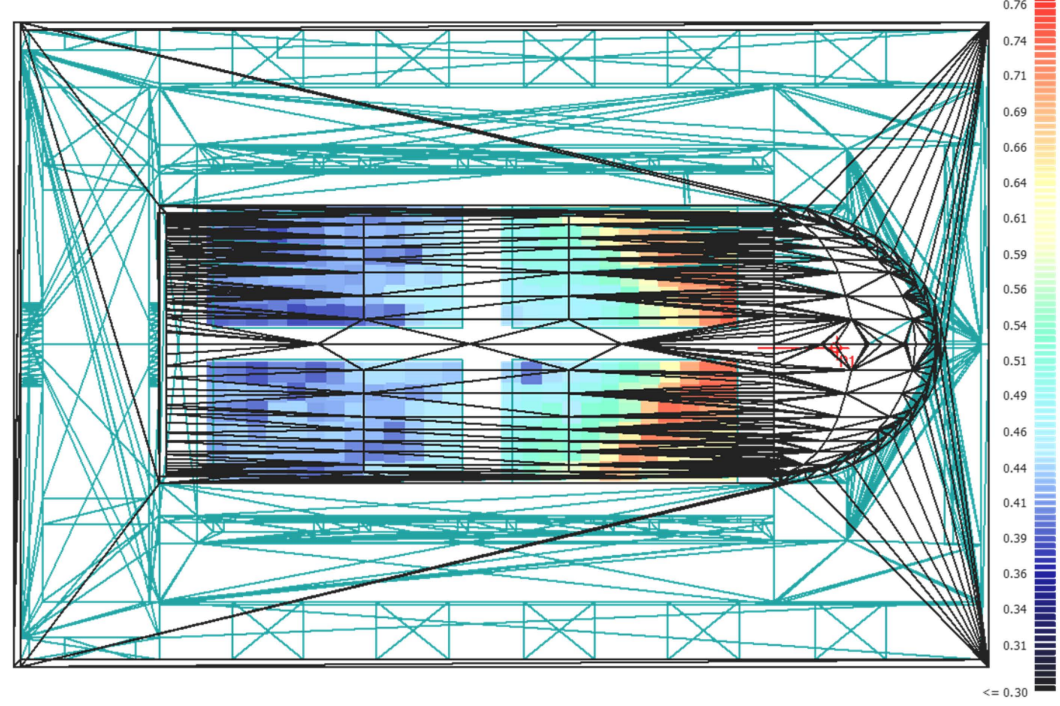

Figure 9. Color maps at $1 \mathrm{kHz}$ of the $\mathrm{T}_{30}, \mathrm{C}_{80}$, and STI in the configuration with the audience and the perforated transparent banners (the maps only cover the area where the audience seats). 


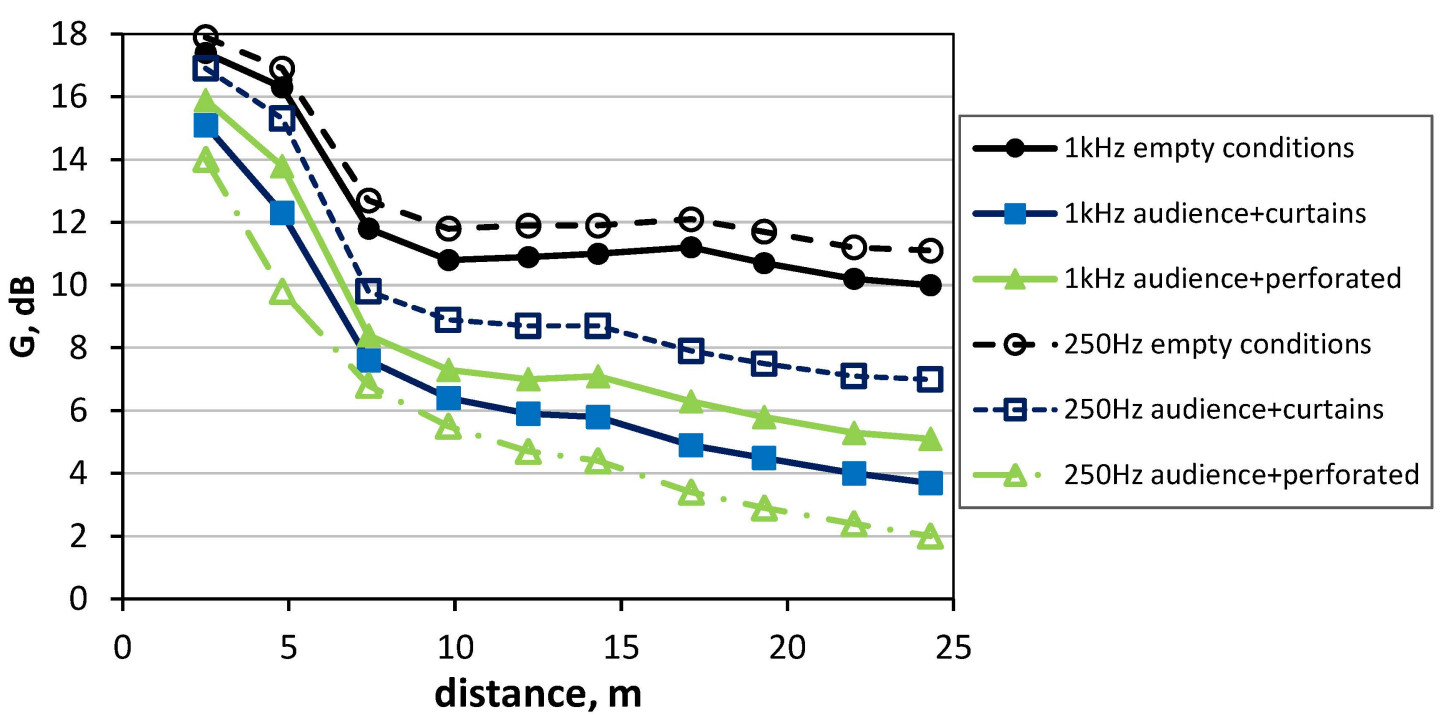

Figure 10. Sound strength $(\mathrm{G})$ at the frequency of $250 \mathrm{~Hz}$ and $1 \mathrm{kHz}$ in different configurations.

A final evaluation of the acoustic interventions presented in this paper regarded the impact of the sound absorption materials over the sound strength. The sound strength was evaluated along the central axes of the Royal Chapel room both at $250 \mathrm{~Hz}$ and $1 \mathrm{kHz}$ (Figure 10). The choice to check the sound absorption at both low and middle frequencies was due to the highly absorptive behavior of the vibrating panels at low frequencies. In fact, although the acoustics intervention with micro perforated vibrating panels aimed to absorb the low frequencies and hence to reduce the frequency unbalanced response of the rom, it was considered important to control the overall sound strength levels.

The sound strength $(\mathrm{G})$ was simulated in different scenarios: in the actual condition, with and without the audience, and after the introduction of the acoustic treatments of the banners. As expected, in the empty condition of the hall, the parameter $G$ has higher values than when the audience and the acoustic treatments are introduced. In particular, in the room before the introduction of the acoustic treatments, the $G$ decreases almost linearly closer to the sound source, while at a larger distance the sound field becomes diffuse and the $\mathrm{G}$ assumes more stable values. Reversely, after the introduction of the acoustics treatments the sound field does not become diffuse quickly, while the sound strength reduces with the distance from the sound source.

\section{Conclusions}

This paper has reported a study about the acoustics in a cultural heritage buildings, the Palatine Chapel in the Royal Palace in Caserta (Italy). Average reverberation times of about $5 \mathrm{~s}$ recorded initially at mid frequencies in unoccupied conditions were deemed inappropriate for the public events hosted in this room nowadays. This situation requires to propose acoustics treatments that could modify the acoustics of the room, while respecting the historical and architectonical value of the room.

Simulation techniques provided useful information for understanding how to improve the acoustics of this room. Firstly, simulations were used for to obtain realistic data about the current acoustics of the room in fully occupied conditions. The study showed that even in fully occupancy conditions, the reverberation time would still be too long. Hence a study of the effects of temporary acoustic treatments compatible with the specific nature of the room was carried out. For this scope, heavy curtains along the lateral walls as well as transparent vibrating panels were considered opportunities to introduce occasionally high sound absorption with minimal aesthetic or visual impact respectively. 
The acoustic treatments that were proposed guaranteed a reduction of the reverberation to about $2.5 \mathrm{~s}$ at middle frequencies. The final acoustic characteristics were therefore considered acceptable for the functions hosted in this chapel while also considering the historical value of this cultural heritage.

Author Contributions: Umberto Berardi, Gino Iannace and Carmine Ianniello contributed equally to this work.

Conflicts of Interest: The authors declare no conflict of interest.

\section{References}

1. United Nations Educational, Scientific and Cultural Organization (UNESCO) World Heritage Sites. Available online: http:/ / whc.unesco.org/en/list (accessed on 21 December 2015).

2. Guide to the Royal Palace of Caserta, (In Italian: Guida Reggia di Caserta). Available online: http://reggiadicaserta.beniculturali.it/index.php/guida-guide/guida-alla-reggia/palazzo/ cappella-palatina.html (accessed on 21 December 2015).

3. Odeon, Version 2011. Room Acoustics Software, Version 11, Combined Edition by Christensen C.L., Odeon A/S, Scion DTU, Lyngby, Denmark. Available online: http://www.odeon.dk/specifications (accessed on 21 December 2015).

4. ISO 3382-1 Acoustics-Measurement of Room Acoustic Parameters-Part 1: Performance Spaces; ISO: Geneva, Switzerland, 2009.

5. Dirac 4.0 Manual, Bruel \& Kjaer. Available online: http://www.bksv.com/ (accessed on 21 December 2015).

6. Berardi, U. A double synthetic index to evaluate the acoustics of churches. Arch. Acoust. 2012, 37, 521-528. [CrossRef]

7. Martellotta, F. Subjective study of preferred listening conditions in italian catholic churches. J. Sound Vib. 2008, 317, 378-399. [CrossRef]

8. Katz, B.F.G. International round robin on room acoustical impulse response analysis software. Acoust. Res. Lett. Online 2004, 5, 158-164. [CrossRef]

9. Krokstad, A.; Strøm, S.; Sørsdal, S. Calculating the acoustical room response by the use of a ray tracing technique. J. Sound Vib. 1968, 8, 118-125. [CrossRef]

10. Patania, F.; Gagliano, A.; Nocera, F.; Galesi, A. Intervention of acoustic correction to improve speech quality of two conference halls in a Sicilian historical building (XVI sec.). In Proceedings of the 38th International Congress on Noise Control Engineering, Ottawa, Canada, 23-26 August 2009.

11. Bork, I. Report on the 3rd round robin on room acoustical computer simulation-Part I: Measurements. Acta Acust. United Acust. 2005, 91, 740-752.

12. Bork, I. Report on the 3rd round robin on room acoustical computer simulation-Part II: Calculations. Acta Acust. United Acust. 2005, 91, 753-763.

13. Zeng, X.; Christensen, C.L.; Rindel, J.H. Practical methods to define scattering coefficients in a room acoustics computer model. Appl. Acoust. 2006, 67, 771-786. [CrossRef]

14. Christensen, C.L.; Koutsouris, G.; Rindel, J.H. The ISO 3382 parameters: Can we simulate them? Can we measure them? In Proceedings of the International Symposium on Room Acoustics, Toronto, ON, Canada, 9-10 June 2013.

15. Galindo, M.; Zamarreno, T.; Girón, S. Acoustic simulations of Mudejar-Gothic churches. J. Acoust. Soc. Am. 2009, 126, 1207-1218. [CrossRef] [PubMed]

16. Vorländer, M. Computer simulations in room acoustics: Concepts and uncertaintie. J. Acoust. Soc. Am. 2013, 133, 1203-1213. [CrossRef] [PubMed]

17. Berardi, U. Simulation of acoustical parameters in rectangular churches. J. Build. Perform. Simul. 2014, 7, 1-16. [CrossRef]

18. Hidaka, T.; Nishihara, N.; Beranek, L.L. Mechanism of sound absorption by seated audiences in concert halls. J. Acoust. Soc. Am. 1996, 100, 2705-2706. [CrossRef]

19. Beranek, L.L.; Hidaka, T. Sound absorption in concert halls by seats, occupied and unoccupied, and by the hall's interior surfaces. J. Acoust. Soc. Am. 1998, 104, 3169-3177. [CrossRef]

20. Alvarez-Morales, L.; Martellotta, F. A geometrical acoustic simulation of the effect of occupancy and source position in historical churches. Appl. Acoust. 2015, 91, 47-58. [CrossRef] 
21. Berardi, U.; Cirillo, E.; Martellotta, F. A comparative analysis of energy models in churches. J. Acoust. Soc. Am. 2009, 126, 1838-1849. [CrossRef] [PubMed]

22. Asdrubali, F.; Pispola, G. Properties of transparent sound-absorbing panels for use in noise barriers. J. Acoust. Soc. Am. 2007, 121, 214-221. [CrossRef]

23. D'Antonio, P.; Cox, T. Technical Bulletin on the Design of Microperforated Transparent Absorbers; RPG Diffusor Systems, Inc., 2005. Available online: http://www.rpginc.com/docs/ Technology/White\%20Papers/Clearsorber\%20White\%20Paper.pdf (accessed on 21 December 2015).

(C) 2015 by the authors; licensee MDPI, Basel, Switzerland. This article is an open access article distributed under the terms and conditions of the Creative Commons by Attribution (CC-BY) license (http://creativecommons.org/licenses/by/4.0/). 